\title{
Mechanical processing of concrete and reinforced concrete with diamond tool
}

\author{
Boris Zhadanovsky ${ }^{1, *}$ \\ ${ }^{1}$ Moscow State University of Civil Engineering, Yaroslavskoye Shosse, 26, Moscow, Russia
}

\begin{abstract}
The technology and organization of construction production using high-performance machines equipped with a diamond tool for machining concrete, concrete and stone surfaces is considered. Various installations, machines and mechanisms with a diamond tool for milling, grinding, drilling and cutting surfaces are presented. The design decisions of the grinding machine MSh-300, installations for machining the surfaces of facing slabs, a high-performance drilling machine and a concrete surface milling cutter are considered. An analysis of domestic and foreign installations has been carried out, which showed that the specific consumption of diamonds in domestic installations is lower with higher productivity. Having studied the sales statistics of manufacturers of individual machines and plants, as well as the positive feedback from implementing construction organizations, it is recommended to use, for the further prospect, high-performance machines and installations with a diamond tool in connection with an increase in the volume of reconstruction of industrial and civil facilities and the construction of transport highways.
\end{abstract}

\section{Introduction}

The increase in the production of domestic natural technical diamonds and significant production of artificial (synthetic) diamonds contributed to the intensive research and design work on the creation and production of modern ma-chines and plants with high-performance diamond tools. During this period, the author of the proposals, with the support of Gosstroy and other state organizations, designed, manufactured, tested and put into production a number of plants and machines for the machining of concrete, reinforced concrete and natural stone equipped with diamond tools [1-4, 15-20].

Methods used for the machining of concrete and reinforced concrete were carried out and studied on a special de-signed stand using samples of concrete and reinforced concrete classes in B 7.5-B 30 .

\section{Methods}

Installations and machines equipped with diamond tools were created on the basis of the received certificates of authorship for inventions and patents. Industrial models were

\footnotetext{
*Corresponding author: aljurgaitis@gmail.com
} 
designed, manufactured and tested. A number of installations and machines for the mechanical treatment of concrete by cutting, drilling, milling and grinding of the above mentioned materials have been supplied or prepared for mass production $[15,16,17,18,19$, 20]. The team of authors of the Special design bureau of the all-Union research Institute of new building materials and JSC "VNII zhelezobeton" developed and manufactured "Installation for surface machining", based on the technical requirements developed, as well as the author's certificate for invention № 313688, published 07.10.1971 Bulletin № 27.

The installation successfully passed industrial tests while producing panels on Silikatnenskiy factory of reinforced concrete constructions and was recommended for serial production Fig. 1).

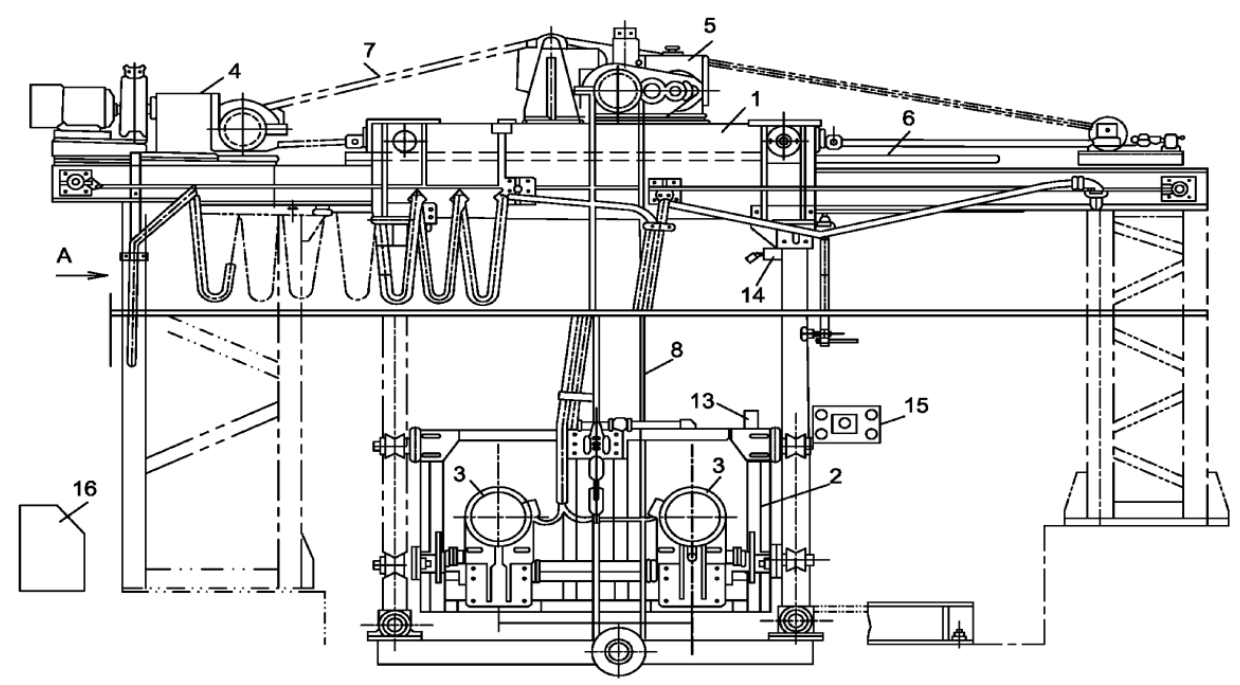

Fig. 1. General view of the installation for surface machining. Where: 1-frame, 2-carriage, 3working body, 4-frame-trolley feeding mechanism, 5-carriage feeding mechanism, 6-upper support beam, 7-chain transmission, 8-rope transmission, 13-cams, 14-limit switch, 15-control panel, 16-electrical cabinet.

The "Installation for tile's surface machining" (Fig. 2, Fig. 3) was developed, passed production tested and recommended for serial production, based on the author's certificate for invention № 482317. Industrial model of the specified installation was put into technological line for production of decorative facing tiles in specially designed for this purpose forms-cassette. Maximum size of tiles $600 \times 600 \mathrm{~mm}$ with a thickness of 30-60 mm. Constructive solutions of the unit are shown in figure 2. Currently, foreign companies do not produce such installations. 


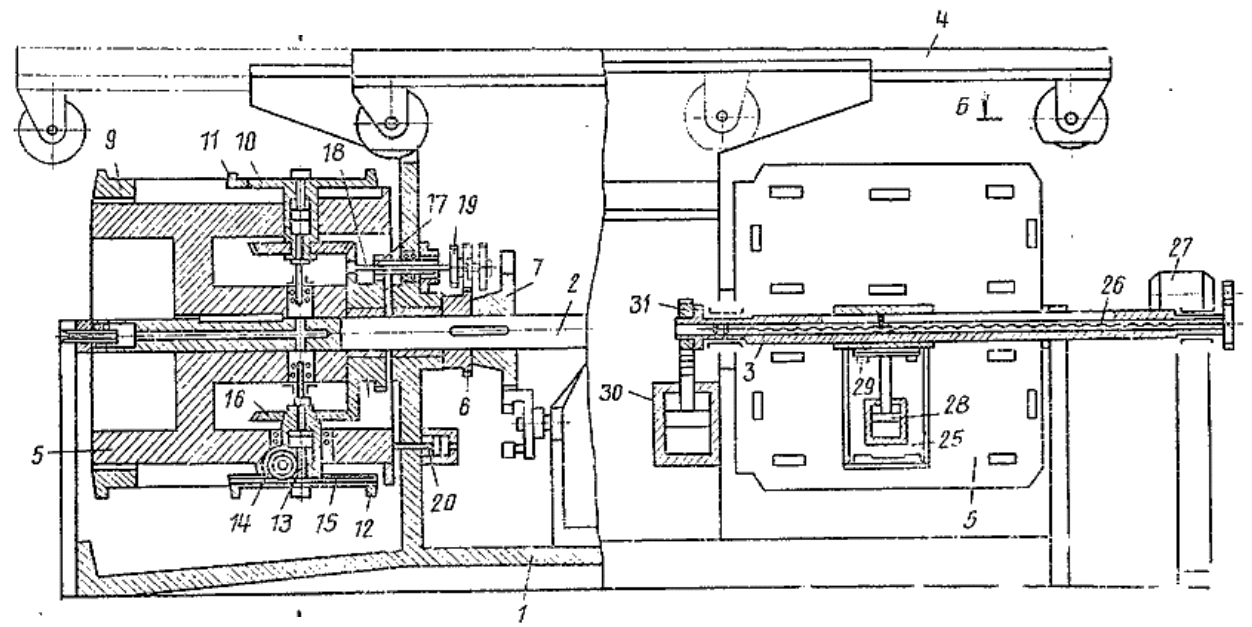

Fig. 2. Constructive solutions of the installation. Where: 1-frame, 2-horizontal shaft, 3-guide rod, 4slides, 5-revolving tables, 6-gears, 7-the Maltese cross, 8-blocks of gears, 9-stops, 10-advanced tables, 11-fixed stops, 12-clamps, 13-power cylinder, 14-gears, 15-rail, 16-end gearwheel, 17- shaft of gears, 18-spline shaft, 19-gear, 20-retainer, 21-diamond or abrasive wheels, 22-remote drives, 23 hollow sleeve, 24-nut, 25-layers, 26-screws, 27- actuators, 28-power cylinder, 29-clamps, 30-air actuator, 31 - pinion-rack drive, 32-pullers, 33-lifts, 34- plate lowering mechanisms (Figure 1).
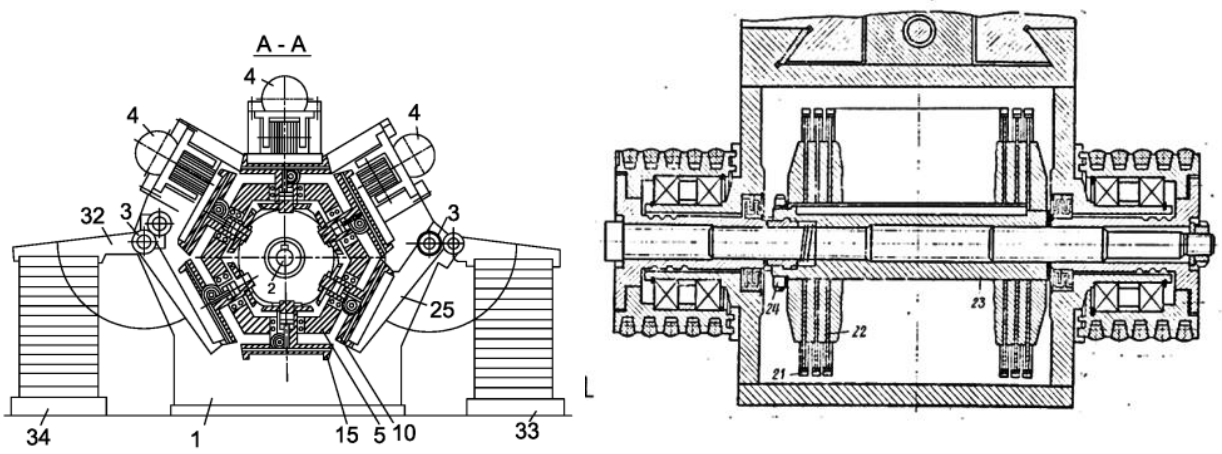

Fig. 3. Installation for tile's surface machining. Where: 1-frame, 2-horizontal shaft, 3-guide rod, 4slides, 5-revolving barrel, 6,8,14-gears, 7-the Maltese cross, 9-stops, 10-barrel, 11 - fixed clamps, 12movable clamps, 13-power cylinder, 15-rail, 16-bevel gear, 17-shaft-gears, 18-spline shaft, 19-gear, 20-clamp, 21-diamond or abrasive wheel, 22-remote drives, 23-hollow sleeve, 24-nut, 25-layers, 26chassis screws, 27-actuator, 28-power cylinder, 29-clamp, 30-air actuator, 31-rack-and-pinion gear, 32-pullers, 33-lifts, 34- plate lowering mechanisms.

TSEKB TSNIIOMTP designed complex installation with independent drive from the pump hydraulic power unit NSH -1628 with replaceable working bodies for cutting stone, concrete and reinforced concrete structures. Four sets of NSH-1628 were contracted in Bulgaria for manufacture and supply. These sets were transferred for production implementation.

Team of developers from TSNIIOMTP and PBK Energostroymechanizatsiya designed two types of machines for grinding concrete preparations and coatings (certificate number 
$607708,25.05 .78$ published in Bulletin No. 19). The de-sign solution of the grinding machine is shown in Pic. 5 (Fig.1 / Fig.2).

The grinding machines MSH 100 and MSH 300 successfully passed factory and production testing and were recommended for serial production.

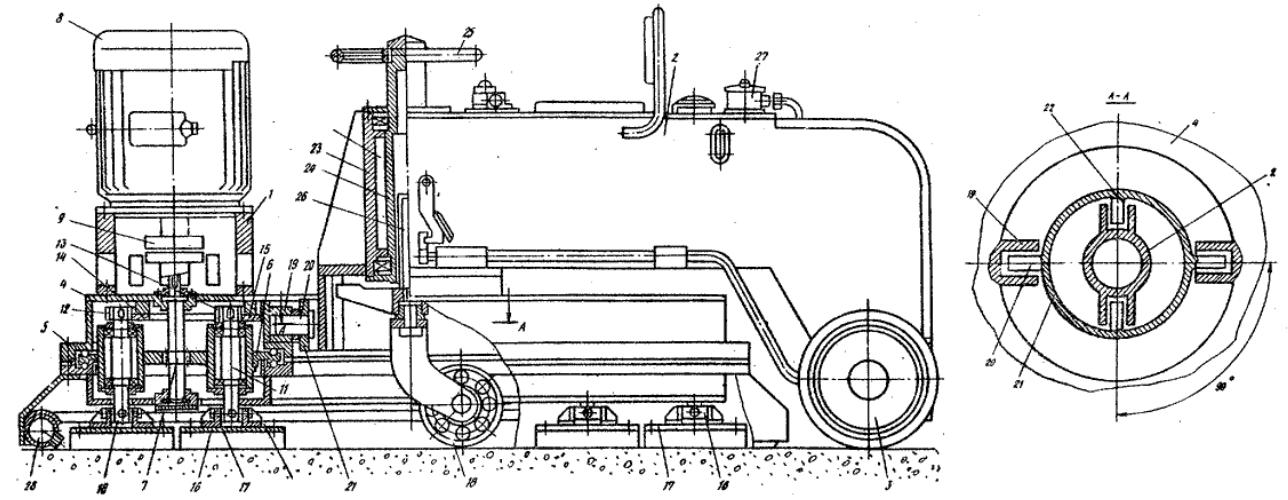

Fig. 4. General design solution of the grinding machine MSH-300. Where: 1-tool head, 2-chassis, 3wheels, 4-ring-shaped housing, 5-6-faceplates, 7-drive, 8-electromotor, 9-piece, 10-11-spindles, 1213-gears, 14-15-toothing, 16-spatial joints, 17-terraces with grinding tool, 18-wheel, 19-lobes, 20 fingers, 21-rings, 22-fingers, 23-column, 24-nut, 25-wheel, 26-screw for wheel lifting and lowering, 27-wheel.

Deployment of authors' research with his contribution was carried out in Pronsk Electromechanical plant of trust "Energostroymekhanizatsiya" (MSH-300, MSH-100, FF100, FF-400) and while grinding concrete surfaces on construction sites of the military unit No. 12253 (surface of $280000 \mathrm{~m} 2$ ).

\section{Results and discussion}

In the domestic construction industry has not yet solved, in full, the problem of milling of concrete pavements, aerodrome pavements, dams, bridges and etc.

The author's certificate for invention No. 1016182 "Concrete surface milling device" is aimed at solving these particular problem.

The design of the installation and machinery was carried out in parallel with the development of organizational-technological documentation and related copyright certificates on inventions referred to in the bibliography.

In addition, drilling machine (patent No. 2059464) should be of particular interest for domestic construction.

NPO "VNIIALMAZ" were conducted acceptance tests of circular segmental diamond drills, manufactured by Kabardino-Balkarian diamond tool factory. 

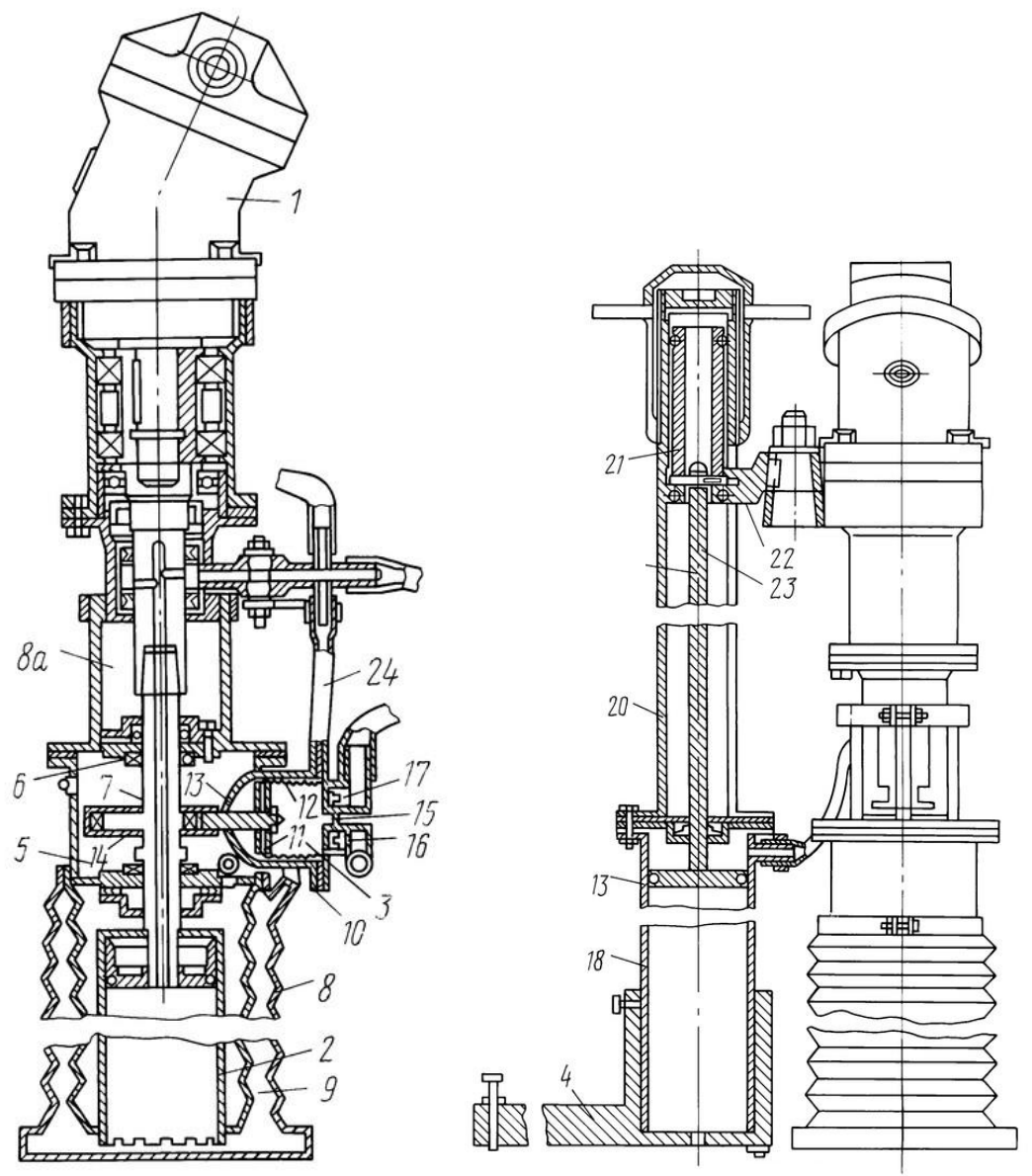

Fig. 5. General constructive solution of drill machine with reverse circulation of water for cooling the tool. Where: 1-hidromotor, 2-ring-drill 3-circulating diaphragm pump, 4-frame, 5-case, 6-bearing, 7shaft, 8-double-walled cuff, 9-perforated layer, 10-diaphragm pump casing, 11-piston, 12-diaphragm, 13-rod, 14-clip, 15-cover, 16-intake, 17-discharge, 18-housing-front, 19-piston, 20-guide stand, 21carriage, 22-console, 23-rod, 24-hoses.

Tests were carried out on production site of trust "Energostroymechanizatsiya" Minenergo (Komarov city). The drills are recommended for serial production. In comparison with foreign analogues, for example, Christensen, the specific consumption of domestic diamond drills is 3.74 carat $/ \mathrm{m}$. against $4.67 \mathrm{carat} / \mathrm{m}$. of foreign analogue and average productivity of domestic drills comes to $2.0 \mathrm{~m} / \mathrm{h}$ against $1.8 \mathrm{~m} / \mathrm{h}$ of foreign analogue [10-14].

Also in early with use of copyright certificates and patents were manufactured, tested and recommended for mass production:

- Device for milling concrete surface (a. c. № 1016182);

- Joints cutter NS-1628 driven by oil-hydraulic stand-alone station completed with boring device (patent No. 2059464).

Engineering fulfillment of scientific and theoretical developments of the author were the design of machines NSH-1628, URBK-2M, SPB-1, FB-100, FB-400, MSH-100, MSH-300, SM-356, SO-189, SO-199, UNB-175, URB-300.

Serial production of machines for diamond drilling of stone, brick, concrete and reinforced concrete, for example, IE-1809, due to the increase in the volume of work, should 
be increased for use in the work performed by the organizations of the Ministry of emergency situations when dismantling the rubble of buildings and structures.

With use of machines and proposals of the author one performed the following work on:

- $\quad$ cutting - 80 thousand r. m.;

- $\quad$ grinding - 500 thousand square meters;

- milling - 256 thousand square meters;

- drilling - 53400 thousand r. m..

Currently, these machines, equipment and diamond tools, developed by domestic scientific-research and design organizations, will be fulfilled in production and will be presented in the domestic construction market in the period of development of the Governmental program on import substitution [10-14].

\section{Conclusions}

Currently the Russian market is mostly saturated with similar machines of foreign manufacture [5-9]. These include, first of all, machines for cutting, milling, drilling and grinding of stone, concrete and reinforced concrete structures, namely manufacturers: «HILTI», «WACKER», «Sundt», «ICS», «JCB», «CEDIMA», «UrtelDiamantwerkzeuge», «WEKA-Elektrowerkzeuge», «Diacom», «PentrudetbyTRACTIVE», «HYDRO-TEC», «SUPERABRASIVE», «Hitachi».

\section{References}

1. State program of the Russian Federation "Energy saving and energy efficiency for the period till 2020, http://www.consultant.ru/document/cons_doc_LAW_109625/ 1c6de4ecab11da862539d19b94ae677f09ba7caa/

2. Russian Standard STO "NOSTROY" 0043363-01-2008, https://rosexpertpravo.ru/law/Data2/1/4293832/4293832623.htm

3. W. Heuson, Product overview, http://wacker-center.ru/conditionwork/ (2013)

4. JCB, Compaction Catalogue, https://docviewer.yandex.ru/view/0/?*=eI\%2BC8Quokg VGhcc7DXAWm4a9ZQ57InVybCI6Imh0dHA6Ly90cy1la2IucnUvYXNzZXRzL2Zp bGVzL3BkZi9jb21wYWN0aW9uLnBkZiIsInRpdGxlIjoiY29tcGFjdGlvbi5wZGYiLC J1aWQiOiIwIiwieXUiOiIzMDAwMzczNzYxNTA2NDU2MzIxIiwibm9pZnJhbWUiO nRydWUsInRzIjoxNTA2OTcyNDgxNTA3fQ\%3D\%3D\&lang=ru

5. S.M. Zhdanov, The journal PGS, 7 (2012)

6. A.V. Kosolapov, E.L. Shkedov, S.A. Krylov, The national Association of diamond cutting and drilling, Diamond cutting and fracture of concrete, Reconstruction technology of bridge structures, Efficient use of diamond equipment and mini-robots for dismantling (2013)

7. A.V. Kosolapov, O.Y. Alekseeva, V.Y. Kazarian, The national Association of diamond cutting and drilling, Construction diamond technology, Diamond cutting and fracture of concrete (2014)

8. V.V. Guryev, The journal PGS, 12 (2008)

9. S.A. Sinenko, B.V. Zhadanovskiy, Science review, 7 (2016)

10. B.V. Zhadanovskiy, Diamond machining technology of building materials and structures (Stroyizdat, 2004) 
11. P.P. Oleynik, B.F. Shyrshykov, Design of construction organization and SMR production, Tutorials for high schools of MSCU (2010)

12. S.N. Bulgakov, Reconstruction of residential houses first mass series and low-rise residential buildings (Globus, 2001)

13. A.A. Afanasev, E.P. Matveev, Reconstruction of residential buildings. Part I. Technology for restoring the operational reliability of residential buildings (2008)

14. P.G. Grabovoy, Reconstruction and renovation of existing buildings of the city (ACB, 2006)

15. B.V. Zhadanovskiy, Installation for machining concrete surfaces, Author's certificate No. 313688 (The Committee for inventions and discoveries, 1988)

16. V.F. Epishin, A method of manufacturing cladding tiles, Author's certificate No. 444755 (The Committee for inventions and discoveries, 1974)

17. B.V. Zhadanovskiy, I.I. Shvartcer, Grinding machine for floors, Author's certificate No. 607708 (The state Committee of the Council of Ministers of the USSR on Affairs of inventions and discoveries, 1978)

18. B.V. Zhadanovskiy, V.F. Epishin, A method of manufacturing tiles from concrete and similar mixtures, Author's certificate No. 358165 (The Committee for inventions and discoveries, 1972)

19. I.I. Shvartcer, V.F. Epishin, Device for milling the concrete surface, Author's certificate No. 1016182 (The state Committee for inventions and discoveries, 1976)

20. B.V. Zhadanovskiy, I.I. Shvartcer, Installation for surface treatment of slabs, Author's certificate No. 482317 (The Committee for inventions and discoveries of the USSR, 1975) 